\title{
Clima organizacional: o caso de uma cooperativa da região fronteira oeste do Rio Grande do Sul
}

\author{
Organizational environment: the case of a cooperative regional border west of Rio \\ Grande do Sul
}

\begin{abstract}
Resumo
Parte-se do entendimento de que quanto mais satisfeito os indivíduos estiverem em uma organização melhor será o seu desempenho individual e coletivo. No caso das cooperativas isso não é diferente, pois um clima organizacional ruim afeta diretamente o desempenho dos colaboradores. Assim, esse artigo pretende analisar o clima organizacional em uma Cooperativa localizada na região da fronteira oeste do Rio Grande do Sul. Para isso, adotou-se uma pesquisa quantitativa, do tipo descritiva, com a coleta de dados realizada através da aplicação de um questionário em uma amostra de 41 funcionários do setor operacional da referida organização. Como resultados, destaca-se que a comunicação e a motivação para o trabalho são fatores positivos, pois existe o reconhecimento, valorização, incentivo à equipe e a cooperação. Entretanto, em relação aos salários e benefícios verificaram-se algumas restrições. Mas, de modo geral, a maioria dos pesquisados manifestou-se satisfeita com o clima organizacional proporcionado pela Cooperativa.
\end{abstract}

Palavras chave: Clima organizacional, Comunicação, Motivação, Cooperativa.

\begin{abstract}
The cooperatives the common goals are reverted to their advantage. However, the organizational environment also directly affects the performance of individuals within this organization and therefore its operation and management. Thus, this article aims to analyze the organizational climate in a cooperative located in the border region west of Rio Grande do Sul. For this, was adopted a quantitative research, descriptive, with data collection performed by applying a questionnaire in sample of 41 employees the organization's operational sector. As a result, it is emphasized that communication and motivation to work are positive factors, as there is recognition, appreciation, encouragement to the team and cooperation. However, in relation to wages and benefits there are some restrictions. But, in general, the majority of respondents expressed satisfaction with the organizational climate provided by the Cooperative.
\end{abstract}

Keywords: Organizational climate, Communication, Motivation, Cooperative.

Recebido: 18/04/2015 Aceito:09/06/2015

\footnotetext{
Vanessa Dalmolin ${ }^{1}$, Élio Sérgio Denardin² e Flaviani Souto Bolzan Medeiros ${ }^{3}$

${ }^{1}$ Centro Universitário Franciscano, Bacharel em Administração - vanessa-dalmolin@ hotmail.com

2 Centro Universitário Franciscano, Mestre em Filosofia - eliodenardin@ hotmail.com

${ }^{3}$ Universidade Federal de Santa Maria, Mestre em Engenharia de Produção - flaviani.13@gmail.com
} 


\section{Introdução}

$\mathrm{N}$ as Cooperativas, como em qualquer outro tipo de organização, devem ser respeitados os direitos e deveres dos indivíduos que trabalham para alcançar os objetivos dessa organização em que estão inseridos. Esses objetivos em comum são em prol deles mesmos, portanto, quanto mais satisfeitos eles estiverem, melhor será o desempenho individual e coletivo.

Com relação aos objetivos da organização, ressalta-se o sentido de alcançar as metas pretendidas para assim obter sucesso financeiro e econômico. Já com relação aos objetivos da comunidade, percebese o sentido de estar inserido e participando desse crescimento e desenvolvimento.

Porém, devido ao processo de globalização da economia, as Cooperativas enfrentam riscos, precisando ser competitivas para sobreviver no mercado e cumprir suas metas de servir seus membros. Para tanto, terão que reduzir seus custos e aprimorar sua gestão, bem como tratar diferentemente seus membros (RODRIGUES, 1997).

Assim, existindo um clima favorável os cooperados podem alcançar metas em comum mais facilmente. Portanto, observa-se que o desenvolvimento desse clima afeta diretamente o desempenho profissional dos indivíduos que integram a Cooperativa e consequentemente o funcionamento e a gestão dessa Cooperativa.

O clima organizacional refere-se ao ambiente de trabalho, ambiente este que para alcançar resultados positivos deve ser o mais agradável possível. Como as Cooperativas são associações que prezam pelo bem comum dos indivíduos, percebe-se a necessidade de haver um ambiente de cooperação onde os colaboradores estejam dispostos a trabalharem em equipe, sempre procurando resultados positivos para a organização.

Também deve haver na organização um conjunto de propriedades mensuráveis no ambiente de trabalho, influenciando assim os trabalhadores de forma positiva na motivação e no comportamento dos mesmos. Esse aspecto influenciador está ligado com a cultura organizacional, políticas de gestão, processo de comunicação, valorizaão profissional e com o processo de cooperação entre os indivíduos.

No entanto, muitos são os conflitos que existem nas Cooperativas que podem dificultar sua forma de gestão. Conforme menciona Luz (2007), o clima organizacional é afetado pelos conflitos e pelos fatores positivos e negativos que ocorrem no ambiente de trabalho, bem como pelos fatores externos que ocorrem no contexto socioeconômico e político, como também, na vida particular dos funcionários.

Assim, nota-se que as Cooperativas possuem inúmeros conflitos na maioria das vezes por não possuir ferramentas para uma gestão eficaz. Além disso, o clima organizacional das Cooperativas é afetado por conflitos de interesses pessoais, como no caso o individualismo de alguns cooperados que podem levar à destruição da coletividade. Entretanto, Bispo (2006, p. 260) menciona que "é por meio da pesquisa de clima organizacional que é possível se medir o nível de relacionamento entre os funcionários e a empresa".

Com base nesse contexto, este artigo tem por objetivo analisar o clima organizacional em uma Cooperativa localizada na região da fronteira oeste do Rio Grande do Sul. O estudo justifica-se pelo fato de que o desenvolvimento humano constitui força vital para a consolidação dos objetivos da organização. Sendo assim, deve-se buscar pelo aumento da produtividade proporcionando um clima organizacional favorável, pois o mesmo é uma das partes fundamentais da gestão de qualquer empresa.

O clima organizacional está ligado à cooperação e motivação dos colaboradores, esta cooperação deve ser tratada como a busca pelos resultados positivos para a Cooperativa, onde esses só serão alcançados com a motivação dos funcionários em realizar bem seu trabalho.

Esse artigo está estruturado em cinco capítulos, a saber: (1) introdução; (2) embasamento teórico com discussões acerca do agronegócio, cooperativismo, bem como clima organizacional; (3) metodologia adotada e suas respectivas classificações; (4) análise e discussão dos resultados a partir do estudo realizado a respeito do clima organizacional na Cooperativa aqui considerada para fins de análise; e (5) no último capítulo visualizam-se as considerações finais. 


\section{Referencial teórico}

\subsection{Agronegócio}

Megido e Xavier (2003) definem o agronegócio como um sistema integrado, uma cadeia de negócios, pesquisa, estudos, ciência, tecnologia etc. desde a origem vegetal/animal até produtos finais com valor agregado - no setor de alimentos, fibras, energia, têxtil, bebidas, couro e outros.

No Brasil, ele chegou a partir da década de 1980, ainda em inglês, onde os primeiros movimentos organizados e sistematizados surgiram de foco, principalmente, em São Paulo e no Rio Grande do Sul. Somente a partir da segunda metade da década de 1980, o termo agronegócio começa a ser aceito e adotado nos livros-textos e jornais (PINHO, 1982).

A comercialização é a parte essencial da produção agropecuária, pois é nela que os esforços de aumento de produtividade e redução de custos, obtidos na produção, podem ser ou não realizados. As perdas decorrentes da comercialização deficiente podem ser grandes o suficiente para inviabilizar uma atividade produtiva, o que coloca as decisões de comercialização entre as principais atividades comerciais (AZEVEDO, 2010).

Segundo Nantes e Scarpelli (2010), com o tempo foi se desenvolvendo um novo posicionamento para as propriedades rurais, em que se busca praticar uma agropecuária moderna e intimamente ligada às agroindústrias ou canais de distribuição. Diante dessa busca de competitividade, as propriedades rurais estão procurando novos modelos para o padrão gerencial e operacional, considerando o consumidor como principal agente definidor dos padrões de qualidade. A redução dos custos de produção e a busca por faturamento fazem parte desse novo modelo produtivo. Para os autores, os empreendimentos rurais caracterizam-se como:

a) Empreendimento rural tradicional: este tipo de empreendimento utiliza equipamentos agrícolas rudimentares, a estrutura organizacional é familiar e as decisões são estritamente empíricas, sujeitas a um alto grau de incerteza. Como consequência, os resultados, em sua grande maioria, são incertos. Esses resultados são dependentes da política agrícola e das condições climáticas, e submetidos aos interesses dos diferentes agentes do processo de comercialização, assim, os resultados obtidos atendem de forma insuficiente às exigências e perspectivas de mercado;

b) Empreendimento rural em transição: nessas propriedades algumas técnicas de produção e de administração já foram introduzidas e, existe a preocupação de permanência no mercado, bem como torná-las empreendimentos competitivos a médio e longo prazo. Os mercados exigem maior diversidade, menores custos, regularidade nas entregas e maior qualidade dos produtos; $\mathrm{e}$

c) Empreendimento rural moderno: é aquele que superou a etapa de transição, estando coordenado com o mercado consumidor e flexível para ajustarse às novas demandas. Assim, é aquele que apresenta equilíbrio entre seus aspectos de capacitação gerencial, adequação tecnológica e desempenho econômico.

Os produtos agroindustriais, segundo mencionam Megido e Xavier (2003) são essencialmente bens de primeira necessidade e de baixo valor unitário. Esse fato faz com que uma variação do preço não afete intensamente sua quantidade consumida, ou seja, no caso de escassez do produto agroindustrial, os preços tendem a subir muito a fim de limitar o consumo. Em contrapartida, quando os produtos agroindustriais são muito abundantes, o preço tende a cair com o propósito de induzir o consumo.

Dessa forma, estas unidades produtivas renunciam, no todo ou em parte, ao exercício independente de certas atividades comunitárias e, se põe a serviço das economias particulares associadas. Portanto, percebe-se a relevância das funções que as Cooperativas exercem, pois são organizações entre as economias particulares dos cooperados, de um lado, e o mercado, de outro, com a missão fundamental outorgada à economia empresarial Cooperativa de servir de intermediária entre o mercado e as economias dos cooperados para promover seu incremento. Isto justifica a denominação de marketing cooperatives, que é a constante avaliação de todo processo de construção dos valores desde a chegada do produto até entrega ao consumidor final, e podendo assim promover a integração do produtor (SOARES NETO, 2010).

\subsection{Cooperativismo}

Schmidt e Vergílio (2003, p. 63) definem cooperativa como "uma associação autônoma de pessoas, 
unida voluntariamente, para atender suas necessidades e aspirações econômicas, sociais e culturais comuns, através de uma empresa coletiva e democraticamente controlada".

Conforme Soares Neto (2010), as cooperativas possuem o objetivo de prestação de serviços a seus associados, ou seja, o "trabalho", e não o lucro como em uma firma de capital. Embora o lucro não seja primordial, ele é necessário para assegurar a viabilidade econômica, a sustentabilidade como empresa e suas opções de crescimento como qualquer outro empreendimento empresarial.

A doutrina cooperativista surgiu em 1844, na Inglaterra, por meio do movimento de um grupo tecelões que fundou uma Cooperativa de consumo denominada Rochdale Society of Equitable Pioners, cujo objetivo era encontrar formas para melhorar sua situação econômica (PINHO, 1982).

De acordo com Schmidt e Vergílio (2003), em 1847, iniciou-se o movimento cooperativista no Brasil, na mesma época surgiu em Santa Catarina, quando o médico francês Jean Maurice Faivre fundou com um grupo de europeus nos sertões do Paraná, a colônia Tereza Cristina, organizada em bases Cooperativas,. Essas organizações, apesar de sua breve existência, contribuíram para a memória coletiva como elemento formador do florescente cooperativo. O cooperativismo orienta-se nas suas atividades, de caráter social e econômico, em um conjunto de valores, de princípios e normas, que devem balizar a sua atuação na economia e na sociedade. Os valores definem as motivações mais profundas do agir cooperativo.

As Cooperativas estão baseadas nos valores da auto-ajuda, responsabilidade própria, democracia, igualdade, equidade e solidariedade. Com base na tradição de seus fundadores, os membros da Cooperativa acreditam nos valores éticos de honestidade, sinceridade, responsabilidade social e preocupação com os outros (SCHMIDT; VERGÍLIO, 2003, p. 63).

Portanto, as Cooperativas são criadas pela união de pessoas que possuem objetivos em comum em prol da economia e da sociedade em que estão inseridas cuja finalidade é proporcionar resultados positivos para seus associados e para a comunidade. Inclusive, Benson (2014) comenta da importância da Cooperativa para os pequenos agricultores, pois os mesmos estariam em desvantagem no mercado no momento de negociar seus produtos.
Sob esse enfoque, Polônio (2004) cita alguns princípios cooperativistas: adesão livre; administração praticada pelos próprios associados; juros módicos do capital social; divisão das sobras para todos associados; neutralidade política, social e religiosa; constituição de um fundo de educação; e cooperação entre Cooperativas, no plano local, nacional e internacional.

$\mathrm{O}$ cooperativismo funciona como um catalisador de negócios e de desenvolvimento e tem como base a cooperação entre as pessoas, promovendo assim a formação de uma empresa que seja competitiva, eficiente e que seja capaz de gerar resultado para seus associados (BAGGIO, 2005).

Cooperação significa ato de cooperar, ou trabalhar em comum, colaborar, sinalizando, portanto, para um sentido de ação e um sentido de movimento coletivo, sempre em oposição à perspectiva individual e individualista. Os processos cooperativos, nos quais se combina o trabalho de muitos trabalhadores, caracterizam-se pela fusão de muitas forças numa força social comum, o que produz um produto global diferente ou maior que a soma das forças individuais dos trabalhadores isolados. Portanto, o aumento da capacidade produtiva não seria o resultado da elevação da força individual de trabalho ou o resultado da soma das forças produtivas individuais, mas da criação de uma força produtiva nova: a força social coletiva, essa força tem sua origem na própria cooperação que pressupõe a coordenação do esforço coletivo para atingir objetivos comuns (JESUS; TIRIBA, 2003).

\subsection{Clima organizacional}

Para Denison (1991), o clima organizacional é um ambiente de qualidade relativamente permanente no interior de uma empresa, experimentado por membros do grupo de uma organização que influencia o seu comportamento e que pode ser descrito de acordo com os valores de um conjunto particular de características dessa organização.

Nesse sentido, o clima organizacional é o reflexo do estado de espírito ou do ânimo das pessoas que predomina em uma empresa em um determinado período. Ressalta-se, ainda, a importância do fator tempo no conceito, uma vez que o clima organizacional é instável, conforme a influência que sofre de algumas variáveis (LUZ, 2007). 
Complementarmente, Sulbarán (2002) comenta que uma das principais funções da gestão é a criação de um clima organizacional positivo, tanto físico como mentalmente, para induzir os indivíduos a contribuir de forma espontânea e voluntariamente com os seus esforços para efetuar a mudança e alcançar objetivos. Sem este ambiente adequado, os esforços dos participantes podem ser ineficazes ou, pior, inválido ou inexistente.

Assim sendo, uma vez que se compreende que o clima organizacional influencia no comportamento dos indivíduos, percebe-se que há alguns fatores como liderança, comunicação e motivação que podem auxiliar na compreensão ou no desenvolvimento do clima na própria empresa.

No caso da liderança, na visão de Stoner e Freeman (1995) ela pode ser definida como o processo de dirigir e influenciar as atividades relacionadas às tarefas dos membros do grupo, onde nessa definição existem três elementos importantes a serem considerados: (1) as pessoas (subordinado ou seguidores); (2) o poder (distribuição desigual entre o líder e os membros do grupo); e (3) a influência (capacidade de influenciar o comportamento dos seguidores).

Cabe frisar ainda que, na gestão do trabalho em equipe, de acordo com Dubrin (1998), são encontrados os estilos de liderança que são classificados de acordo com a autoridade retida e a aplicada para o grupo. Os estilos podem ser autocrático, democrático e liberal.

O comportamento autocrático corresponde ao uso propriamente dito da autoridade formal, e suprime a participação ou influência dos subordinados no processo decisório; enquanto que na liderança democrática há participação dos subordinados no processo de tomada de decisões, já na liderança liberal o líder transfere seu poder aos subordinados (MAXIMIANO, 2011).

A respeito da comunicação, através dela é possível dar e receber informações, conhecimento, sendo ela a maior forma de influenciar pessoas e muito utilizada pelos líderes das organizações neste processo de influência. Também há grande importância na integração dos grupos de trabalho, proporcionando uma maior interação entre os participantes. A comunicação é compreendida no momento em que a necessidade do ser humano de trabalhar em conjunto determina o estabelecimento de relações entre homens e natureza, e entre os próprios homens. Como consequência dessas relações deve manifestar-se, portanto, a cooperação (RÜDIGER, 2003).

Sobre a motivação, Robbins (2000, p. 342) acredita que "a motivação é a disposição de exercer um nível elevado e permanente de esforço em favor das metas da organização, sob a condição de que o esforço seja capaz de satisfazer alguma necessidade individual".

Dias e Stocco (2006) concordam com o exposto entendendo que os trabalhadores estarão motivados a produzir mais quando acreditarem que o esforço deles trará uma boa avaliação de desempenho, consequentemente, isso trará recompensas organizacionais, assim, eles poderão satisfazer suas metas pessoais.

\section{Metodologia}

Metodologicamente, adotou-se uma pesquisa quantitativa quanto à natureza dos dados, do tipo descritiva segundo os objetivos (GONSALVES, 2012). Deste modo, sobre a pesquisa quantitativa Michel (2009) explica que sua realização preza pela busca de resultados precisos, exatos, comprovados através de medidas de variáveis preestabelecidas, na qual se procura verificar e explicar sua influência sobre outras variáveis.

No caso da pesquisa descritiva, Gil (2010) comenta que essa tem como propósito a descrição das características de determinadas populações ou fenômenos, sendo que uma delas está na utilização de técnicas padronizadas de coleta de dados, tais como o questionário.

Como plano de coleta dos dados, primeiramente, realizou-se uma pesquisa bibliográfica acerca do tema abordado. Posteriormente, com base na literatura, foi elaborado pelos autores um questionário composto por 28 perguntas fechadas, de múltipla escolha, sendo aplicado em uma amostra de 41 funcionários do setor operacional da Cooperativa. Essa amostragem foi do tipo não probabilística, intencional por orientação da direção, extraída de uma população total de 70 funcionários do setor.

Esse estudo foi realizado em uma Cooperativa que atua há mais de 60 anos no mercado e possui seu negócio voltado para a agroindústria de armazenagem, beneficiamento e comércio de cereais, possuindo um total de 86 funcionários, divididos nos setores industrial, administrativo, comercial e 
financeiro. Os dados obtidos foram tabulados com o auxílio do software Sphinx Léxica ${ }^{\circledR}$ versão 5.

\section{Análise e discussão dos resultados}

A análise do perfil dos pesquisados mostrou que $100 \%$ são do sexo masculino. Constatou-se ainda que $12,2 \%$ trabalham na Cooperativa há menos de 1 ano, outros $9,8 \%$ possuem de 1 a 2 anos de serviço, $14,6 \%$ de 3 a 5 anos de serviço, 9,8\% trabalham de 6 a 10 anos, já $24,4 \%$ possuem de 11 a 20 de serviço, enquanto que $12,2 \%$ trabalham de 21 a 30 anos, 2,4\% estão há mais de 30 anos na Cooperativa, e ainda 14,6\% não opinaram. Percebe-se uma elevada estabilidade na Cooperativa em relação ao tempo de serviço dos funcionários.

Observou-se na Tabela 1, que 43,90\% dos entrevistados concordam e $24,39 \%$ concordam totalmente que a missão, os valores e os objetivos são claramente definidos, totalizando assim um percentual de $68,29 \%$. Entretanto, 24,39\% dizem não conhecer a missão, os valores e os objetivos e 7,32\% são indiferentes ao item. Portanto, sugere-se que a Cooperativa informe sua missão, valores e objetivos, pois são fundamentais para o bom desempenho das atividades.

Tabela 1 - A missão, os valores e objetivos da Cooperativa são claramente definidos

\begin{tabular}{lcc}
\hline \multicolumn{1}{c}{ Clareza na definição } & Frequência & Percentual \\
\hline Discordo totalmente & 0 & $0,00 \%$ \\
Discordo & 10 & $24,39 \%$ \\
Indiferente & 3 & $7,32 \%$ \\
Concordo & 18 & $43,90 \%$ \\
Concordo totalmente & 10 & $24,39 \%$ \\
Total & 41 & $100,00 \%$ \\
\hline
\end{tabular}

Fonte: Elaborada pelos autores com base nos dados da pesquisa.

Tabela 2 - A comunicação do chefe com os funcionários é clara

\begin{tabular}{lcc}
\hline \multicolumn{1}{c}{ Comunicação do chefe } & Frequência & Percentual \\
\hline Discordo totalmente & 11 & $26,83 \%$ \\
Discordo & 1 & $2,44 \%$ \\
Indiferente & 2 & $4,88 \%$ \\
Concordo & 19 & $46,34 \%$ \\
Concordo totalmente & 8 & $19,51 \%$ \\
Total & 41 & $100,00 \%$ \\
\hline
\end{tabular}

Fonte: Elaborada pelos autores com base nos dados da pesquisa.

As Tabelas 2 e 3 mostram a relação da comunicação do chefe para com os funcionários e a comunicação entre os funcionários.

Destacou-se na Tabela 2 que 46,34\% dos funcionários concordam e 19,51\% concordam totalmente que a comunicação do chefe com os funcionários dizem ser clara. Porém, 26,83\% dos pesquisados discordam totalmente e $2,44 \%$ discordam dessa afirmação, pois acreditam que a chefia não se expressa com clareza. Os restantes $4,88 \%$ são indiferentes. 
Tabela 3 - Problemas de comunicação entre chefe e funcionários e entre funcionários

\begin{tabular}{lcccc}
\hline \multirow{2}{*}{ Problemas de comunicação } & \multicolumn{2}{c}{ Entre chefe e funcionários } & \multicolumn{2}{c}{ Entre funcionários } \\
Frequência & Percentual & Frequência & Percentual \\
\hline Não responderam & 1 & $2,44 \%$ & 0 & $0,00 \%$ \\
Discordo totalmente & 6 & $14,63 \%$ & 10 & $24,39 \%$ \\
Discordo & 14 & $34,15 \%$ & 15 & $36,59 \%$ \\
Indiferente & 2 & $4,88 \%$ & 6 & $14,63 \%$ \\
Concordo & 10 & $24,39 \%$ & 7 & $17,07 \%$ \\
Concordo totalmente & 8 & $19,51 \%$ & 3 & $7,32 \%$ \\
Total & 41 & $100,00 \%$ & 41 & $100,00 \%$ \\
\hline
\end{tabular}

Fonte: Elaborada pelos autores com base nos dados da pesquisa.

Através da Tabela 3 pode-se verificar que $34,15 \%$ dos respondentes discordam e $14,63 \%$ discordam totalmente que existam problemas de comunicação entre o chefe e os funcionários. Mas, $24,39 \%$ concordam e $19,51 \%$ concordam totalmente que a comunicação entre o chefe e os funcionários não está boa. Já 4,88\% são indiferentes ao exposto e o restante $(2,44 \%)$ não opinaram. Percebese que as opiniões encontram-se divididas quanto à existência de problemas.

Quanto a problemas de comunicação entre os funcionários, percebe-se que $36,59 \%$ dos pesquisa- dos discordam e $24,39 \%$ discordam totalmente que existem. Já $17,07 \%$ concordam e 7,32\% concordam totalmente sobre a existência desses problemas, os 14,63\% restantes são indiferentes a essa questão.

Destaca-se na Tabela 4, que 43,90\% dos funcionários concordam e 7,32\% concordam totalmente que utilizam o diálogo para resolver conflitos. Porém, $9,75 \%$ discordam e $4,88 \%$ discordam totalmente da utilização do diálogo, já 2,44\% não responderam e $31,71 \%$ são indiferentes.

Tabela 4 - É utilizado diálogo para resolver conflitos

\begin{tabular}{lcc}
\hline \multicolumn{1}{c}{ Diálogos para conflitos } & Frequência & Percentual \\
\hline Não responderam & 1 & $2,44 \%$ \\
Discordo totalmente & 2 & $4,88 \%$ \\
Discordo & 4 & $9,75 \%$ \\
Indiferente & 13 & $31,71 \%$ \\
Concordo & 18 & $43,90 \%$ \\
Concordo totalmente & 3 & $7,32 \%$ \\
Total & 41 & $100,00 \%$ \\
\hline
\end{tabular}

Fonte: Elaborada pelos autores com base nos dados da pesquisa.

Esses dados vêm confirmar o exposto por Robbins (2000), ou seja, que para a comunicação ter êxito é necessário que o significado seja entendido. Portanto, como forma de solucionar o processo de comunicação entre chefe e funcionários e entre os funcionários, sugere-se que esses pontos sejam tratados pelo gerente em reunião, pois a comunicação exerce grande influencia nos relacionamentos e no desempenho das atividades.

Constatou-se em relação ao relacionamento de respeito e cooperação entre os colegas de trabalho que $31,7 \%$ dos funcionários concordam totalmente e $29,3 \%$ concordam que isso existe na Cooperativa. Entretanto, $19,5 \%$ discordam totalmente e 14,6\% discordam da afirmação, outros 4,9\% são indiferentes ao item. Embora, $61 \%$ dos funcionários percebem um relacionamento positivo, ainda pode ser melhorado através de uma conscientização de sua importância no trabalho em equipe e de um treinamento efetivo. 
Tabela 5 - Há sensibilidade e compreensão do chefe com os funcionários

\begin{tabular}{lcc}
\hline \multicolumn{1}{c}{ Sensibilidade do chefe } & Frequência & Percentual \\
\hline Discordo totalmente & 11 & $26,83 \%$ \\
Discordo & 2 & $4,88 \%$ \\
Indiferente & 7 & $17,07 \%$ \\
Concordo & 12 & $29,27 \%$ \\
Concordo totalmente & 9 & $21,95 \%$ \\
Total & 41 & $100,00 \%$ \\
\hline
\end{tabular}

Fonte: Elaborada pelos autores com base nos dados da pesquisa.

Os dados da Tabela 5 revelam que 29,27\% dos funcionários concordam com a afirmação exposta e, ainda, $21,95 \%$ concordam totalmente, o que somados atinge um percentual de $51,22 \%$ que conside- ram que o chefe possui sensibilidade e compreensão de entender os problemas dos funcionários. Porém, $26,83 \%$ discordam totalmente e outros $4,88 \%$ discordam, e $17,07 \%$ são indiferentes.

Tabela 6 - A chefia possui a capacidade de influenciar e incentivar a equipe de trabalho

\begin{tabular}{lcc}
\hline \multicolumn{1}{c}{ Chefia influencia a equipe } & Frequência & Percentual \\
\hline Discordo totalmente & 1 & $2,44 \%$ \\
Discordo & 14 & $34,15 \%$ \\
Indiferente & 4 & $9,75 \%$ \\
Concordo & 14 & $34,15 \%$ \\
Concordo totalmente & 8 & $19,51 \%$ \\
Total & 41 & $100,00 \%$ \\
\hline
\end{tabular}

Fonte: Elaborada pelos autores com base nos dados da pesquisa.

De acordo com a Tabela 6, observou-se que $34,15 \%$ dos respondentes concordam e que $19,51 \%$ concordam totalmente, perfazendo $53,66 \%$, que o chefe possui a capacidade de influenciar e motivar a equipe de trabalho. Todavia, $34,15 \%$ dos respondentes discordam e $2,44 \%$ discordam totalmente desta capacidade e os demais $9,75 \%$ se mostraram indiferentes à questão.

Tabela 7 - O seu trabalho não é devidamente reconhecido e valorizado

\begin{tabular}{lcc}
\hline \multicolumn{1}{c}{ Reconhecimento do trabalho } & Frequência & Percentual \\
\hline Discordo totalmente & 7 & $17,07 \%$ \\
Discordo & 15 & $36,60 \%$ \\
Indiferente & 6 & $14,63 \%$ \\
Concordo & 6 & $14,63 \%$ \\
Concordo totalmente & 7 & $17,07 \%$ \\
Total & 41 & $100,00 \%$ \\
\hline
\end{tabular}

Fonte: Elaborada pelos autores com base nos dados da pesquisa.

Na Tabela 7 verificou-se que $36,60 \%$ dos funcionários discordam e $17,07 \%$ discordam totalmente que o seu trabalho não é devidamente reconhecido e valorizado, somando 53,67\%. Já, 17,07\% concor- dam totalmente e $14,63 \%$ concordam com a afirmação, e outros 14,63\% são indiferentes.

Constatou-se, de modo geral, um resultado positivo nesses itens avaliados. Como a sensibilidade e compreensão, a capacidade de influenciar e incenti- 
var e o reconhecimento e a valorização do trabalho do funcionário pela chefia são fatores de grande impacto na produtividade da Cooperativa, sugere-se à gerência que procure buscar uma melhoria continua através do diálogo com os funcionários.

Tabela 8 - A gestão do trabalho em equipe proporciona um nível de satisfação elevado

\begin{tabular}{lcc}
\hline \multicolumn{1}{c}{ Satisfação } & Frequência & Percentual \\
\hline Não responderam & 1 & $2,44 \%$ \\
Discordo totalmente & 2 & $4,88 \%$ \\
Discordo & 5 & $12,20 \%$ \\
Indiferente & 11 & $26,83 \%$ \\
Concordo & 18 & $43,90 \%$ \\
Concordo totalmente & 4 & $9,75 \%$ \\
Total & 41 & $100,00 \%$ \\
\hline
\end{tabular}

Fonte: Elaborada pelos autores com base nos dados da pesquisa.

Destaca-se na Tabela 8 que 43,90\% dos funcionários concordam e $9,75 \%$ concordam totalmente que o trabalho em equipe na busca dos objetivos e metas organizacionais proporciona um nível de satisfação elevado aos colaboradores, somando um percentual de 53,65\%.

Entretanto, $12,20 \%$ discordam e $4,88 \%$ discordam totalmente, totalizando $17,08 \%$, outros $2,44 \%$ não opinaram e, ainda, $26,83 \%$ são indiferentes ao questionamento. Diante de tais resultados, cabe trazer o apontamento feito por Hashimoto (2009, p. 23), ou seja, "desenvolver um clima de trabalho que aumente a satisfação dos funcionários é uma das condições necessárias para se atingir desempenho superior".

Quando questionados sobre estar motivado e comprometido com as metas e objetivos Cooperativa, observou-se que $41,46 \%$ dos pesquisados concordam e $24,39 \%$ concordam totalmente com o ex- posto, perfazendo $65,85 \%$. Já, 21,95\% discordam totalmente e $7,32 \%$ discordam, enquanto que $4,88 \%$ são indiferentes.

Em relação a sentir orgulho por trabalhar na organização, constatou que $34,15 \%$ dos respondentes concordam totalmente e $34,15 \%$ concordam que se orgulham de trabalhar na Cooperativa, totalizando $68,3 \%$. Entretanto, $9,75 \%$ discordam e $2,44 \%$ discordam totalmente do exposto, outros $4,88 \%$ não responderam e $14,63 \%$ se mostraram indiferentes.

Portanto, pode-se dizer nesses itens que os resultados são positivos, pois o reconhecimento e a valorização no trabalho elevam o nível de satisfação e proporciona um sentimento favorável pela empresa, o que vai ao encontro de Robbins (2000) que menciona que a motivação é a disposição de exercer elevado e permanente esforço em favor das metas da organização.

Tabela 9 - A liberdade de expressão e autonomia não são suficientes

\begin{tabular}{lcc}
\hline Liberdade de expressão e autonomia & Frequência & Percentual \\
\hline Discordo totalmente & 5 & $12,20 \%$ \\
Discordo & 11 & $26,83 \%$ \\
Indiferente & 10 & $24,39 \%$ \\
Concordo & 12 & $29,26 \%$ \\
Concordo totalmente & 3 & $7,32 \%$ \\
Total & 41 & $100,00 \%$ \\
\hline
\end{tabular}

Fonte: Elaborada pelos autores com base nos dados da pesquisa.

Observa-se na Tabela 9 que $29,26 \%$ dos pesquisados concordam e 7,32\% concordam totalmente que a liberdade de expressão e a autonomia dada pela Cooperativa não é suficiente para executar o seu trabalho, totalizando 36,58\%. Entretanto, $26,83 \%$ discordam e $12,20 \%$ discordam totalmente 
da afirmação, totalizando $39,03 \%$, outros $24,39 \%$ são indiferentes ao exposto.

A pesquisa demonstrou um dado positivo no sentido de dar abertura na execução do trabalho, para melhorar ainda mais o processo de liberdade de expressão e autonomia a Cooperativa pode estudar alguns meios de participação dos funcionários no processo de execução do trabalho.

Tabela 10 - Existe abertura para críticas e sugestões por parte da direção

\begin{tabular}{lcc}
\hline \multicolumn{1}{c}{ Abertura a críticas } & Frequência & Percentual \\
\hline Discordo totalmente & 10 & $24,39 \%$ \\
Discordo & 10 & $24,39 \%$ \\
Indiferente & 6 & $14,63 \%$ \\
Concordo & 13 & $31,71 \%$ \\
Concordo totalmente & 2 & $4,88 \%$ \\
Total & 41 & $100,00 \%$ \\
\hline
\end{tabular}

Fonte: Elaborada pelos autores com base nos dados da pesquisa.

Ao analisar a Tabela 10 nota-se que $24,39 \%$ dos funcionários discordam totalmente e $24,39 \%$ discordam da existência de abertura para críticas e sugestões por parte da direção. Todavia, 31,71\% concordam e $4,88 \%$ concordam totalmente com o questionamento, enquanto que $14,63 \%$ são indiferentes.

Sobre a participação da equipe na tomada de decisão com os superiores, verificou-se que 39,01\% dos funcionários discordam e 12,20\% discordam totalmente que ocorre a participação dos funcionários. Já, 21,95\% dos entrevistados concordam e $12,20 \%$ concordam totalmente que exista participação, outros $2,44 \%$ não responderam e ainda $12,20 \%$ se mostraram indiferentes ao item.
Diante de tais resultados, constata-se que a Cooperativa apresenta um estilo de liderança autocrático. Nesse caso, não existe o envolvimento do grupo no processo de tomada de decisão, sendo um estilo no qual apenas o líder é quem determina as tarefas a serem executadas (PINTO; GOMES, 2014).

Verifica-se na Tabela 11 que 36,59\% dos pesquisados concordam e $26,83 \%$ concordam totalmente que os treinamentos oferecidos pela Cooperativa são importantes para o aperfeiçoamento pessoal e para desenvolver suas atividades, totalizando $63,42 \%$. Entretanto, 9,75\% discordam e 7,32\% discordam totalmente que os treinamentos são importantes para tal fim e, $19,51 \%$, são indiferentes à questão.

Tabela 11 - Importância do treinamento

\begin{tabular}{lcc}
\hline \multicolumn{1}{c}{ Treinamentos } & Frequência & Percentual \\
\hline Discordo totalmente & 3 & $7,32 \%$ \\
Discordo & 4 & $9,75 \%$ \\
Indiferente & 8 & $19,51 \%$ \\
Concordo & 15 & $36,59 \%$ \\
Concordo totalmente & 11 & $26,83 \%$ \\
Total & 41 & $100,00 \%$ \\
\hline
\end{tabular}

Fonte: Elaborada pelos autores com base nos dados da pesquisa.

No que se refere aos instrumentos e equipamentos serem adequados para execução do trabalho destaca-se que $41,47 \%$ dos respondentes concordam e que $14,63 \%$ concordam totalmente que os instrumentos e equipamentos são adequados, totalizando uma média de 56,09\%. Porém, 17,07\% discordam e
2,44\% discordam totalmente dessa afirmação, outros $24,39 \%$ são indiferentes.

Em relação às condições físicas e de segurança deixarem a desejar constatou-se que $46,35 \%$ dos pesquisados discordam e $17,07 \%$ discordam totalmente que as condições físicas e de segurança dei- 
xam a desejar. Já, 9,75\% concordam e 2,44\% concordam totalmente com a afirmação. Porém, $21,95 \%$ são indiferentes ao item e 2,44\% não opinaram. Sugere-se que a Cooperativa conscientize seus funcionários sobre a existência desses equipamentos de segurança.
Pela análise na Tabela 12, percebe-se que $34,15 \%$ dos pesquisados concordam e $17,07 \%$ concordam totalmente que os membros da equipe colaboram na realização das atividades. Porém, 21,95\% discordam e $12,20 \%$ discordam totalmente do exposto e, ainda, $14,63 \%$ restantes são indiferentes.

Tabela 12 - Os membros da equipe colaboram na realização das atividades

\begin{tabular}{lcc}
\hline \multicolumn{1}{c}{ Colaboração dos membros da equipe } & Frequência & Percentual \\
\hline Discordo totalmente & 5 & $12,20 \%$ \\
Discordo & 9 & $21,95 \%$ \\
Indiferente & 6 & $14,63 \%$ \\
Concordo & 14 & $34,15 \%$ \\
Concordo totalmente & 7 & $17,07 \%$ \\
Total & 41 & $100,00 \%$ \\
\hline
\end{tabular}

Fonte: Elaborada pelos autores com base nos dados da pesquisa.

Tabela 13 - O salário corresponde ao mercado de trabalho/Justo quanto ao desempenho

\begin{tabular}{|c|c|c|c|c|}
\hline \multirow[b]{2}{*}{ Itens } & \multicolumn{2}{|c|}{ Corresponde ao mercado } & \multicolumn{2}{|c|}{ É justo quanto ao desempenho } \\
\hline & Frequência & Percentual & Frequência & Percentual \\
\hline Discordo totalmente & 13 & $31,71 \%$ & 18 & $43,90 \%$ \\
\hline Discordo & 8 & $19,51 \%$ & 7 & $17,07 \%$ \\
\hline Indiferente & 4 & $9,75 \%$ & 2 & $4,88 \%$ \\
\hline Concordo & 15 & $36,59 \%$ & 13 & $31,71 \%$ \\
\hline Concordo totalmente & 1 & $2,44 \%$ & 1 & $2,44 \%$ \\
\hline Total & 41 & $100,00 \%$ & 41 & $100,00 \%$ \\
\hline
\end{tabular}

Fonte: Elaborada pelos autores com base nos dados da pesquisa.

Tabela 14 - Os benefícios atendem as necessidades pessoais

\begin{tabular}{lcc}
\hline \multicolumn{1}{c}{ Benefícios } & Frequência & Percentual \\
\hline Discordo totalmente & 11 & $26,83 \%$ \\
Discordo & 10 & $24,39 \%$ \\
Indiferente & 1 & $2,44 \%$ \\
Concordo & 15 & $36,59 \%$ \\
Concordo totalmente & 4 & $9,75 \%$ \\
Total & 41 & $100,00 \%$ \\
\hline
\end{tabular}

Fonte: Elaborada pelos autores com base nos dados da pesquisa.

As Tabelas 13 e 14 correspondem ao salário dos funcionários e os benefícios oferecidos pela Cooperativa.

Constatou-se na Tabela 13 que $31,71 \%$ dos respondentes discordam totalmente e $19,51 \%$ discor- dam que o salário pago pela Cooperativa corresponde ao mercado de trabalho, atingindo um percentual de 51,22\%. Entretanto, 36,59\% concordam e $2,44 \%$ concordam totalmente com o questiona- 
mento, enquanto que restantes $(9,75 \%)$ são indiferentes ao item.

Em relação ao salário ser justo de acordo com o desempenho, 43,90\% dos pesquisados discordam totalmente, $17,07 \%$ discordam, totalizando um percentual de $60,97 \%$. Porém, $31,71 \%$ concordam e $2,44 \%$ concordam totalmente que o salário pago é justo e $4,88 \%$ são indiferentes.

Destaca-se na Tabela 14 que 26,83\% discordam totalmente e $24,39 \%$ discordam que os benefícios oferecidos pela empresa não atendem as necessidades pessoais, totalizando uma média de 51,22\%. Entretanto, 36,59\% concordam e 9,75\% concordam totalmente com o questionamento, outros $2,44 \%$ se mostraram indiferentes ao item.
Quando questionados sobre a Cooperativa ter programas de incentivo atraentes para a evolução da carreira de seus funcionários, verificou-se que $29,27 \%$ discordam totalmente e $29,27 \%$ discordam da afirmação. Já, 12,20\% concordam e 12,20\% concordam totalmente que a empresa possui programas de incentivo e, outros $17,06 \%$ são indiferentes.

Dessa forma, sugere-se que a Cooperativa procure disponibilizar um plano de carreira para seus funcionários, um salário adequado às competências de cada um para que os mesmos sintam-se motivados e reconhecidos na organização.

Tabela 15 - O esforço em atingir as metas da Cooperativa influencia as metas pessoais

\begin{tabular}{lcc}
\hline \multicolumn{1}{c}{ Atinjam metas } & Frequência & Percentual \\
\hline Discordo totalmente & 12 & $29,27 \%$ \\
Discordo & 4 & $9,75 \%$ \\
Indiferente & 3 & $7,32 \%$ \\
Concordo & 15 & $36,59 \%$ \\
Concordo totalmente & 7 & $17,07 \%$ \\
Total & 41 & $100,00 \%$ \\
\hline
\end{tabular}

Fonte: Elaborada pelos autores com base nos dados da pesquisa.

Observou-se na Tabela 15 que 36,59\% dos pesquisados concordam e $17,07 \%$ concordam totalmente que o esforço dos funcionários para a obtenção das metas da empresa faz com que eles atinjam suas metas pessoais. Entretanto, 29,27\% discordam totalmente e $9,75 \%$ discordam da afirmação e, ainda, 7,32\% restantes são indiferentes ao questionamento. Pela Tabela 16 observa-se se o clima organizacional é favorável para o trabalho.

Tabela 16 - O clima da organização de modo geral é favorável para o trabalho

\begin{tabular}{lcc}
\hline \multicolumn{1}{c}{ Clima favorável } & Frequência & Percentual \\
\hline Discordo totalmente & 6 & $14,63 \%$ \\
Discordo & 3 & $7,32 \%$ \\
Indiferente & 4 & $9,75 \%$ \\
Concordo & 19 & $46,35 \%$ \\
Concordo totalmente & 9 & $21,95 \%$ \\
Total & 41 & $100,00 \%$ \\
\hline
\end{tabular}

Fonte: Elaborada pelos autores com base nos dados da pesquisa.

Percebe-se na Tabela 16 que $46,35 \%$ dos pesquisados concordam e $21,95 \%$ concordam totalmente que o clima organizacional é favorável para a realização do seu trabalho, totalizando $68,30 \%$. Porém, $14,63 \%$ discordam totalmente, $7,32 \%$ discordam que o clima seja favorável e, $9,75 \%$ se mostraram indiferentes.

Ao findar esse estudo acredita-se que tenha ficado mais claro a questão da caracterização de qualquer organização estar relacionada com o seu clima 
organizacional, em uma relação entre os indivíduos que cooperam entre si para que os objetivos previamente definidos sejam alcançados.

Isso porque essa relação de cooperação entre a equipe de trabalho aplica-se a todo tipo de organização e não apenas as Cooperativas. Inclusive, Maia et al. (2014) reforça que apesar de existirem algumas diferenças entre as organizações tradicionais e o cooperativismo, observa-se que não são totalmente excludentes uma à outra.

Deste modo, quando o clima organizacional é bom essa relação entre os indivíduos e empresa acontece de uma forma muito mais agradável para ambas às partes. Também cabe destacar que a cooperação e o clima existente em uma organização são partes fundamentais para a elaboração das estratégias que deverão ser seguidas para o alcance dos objetivos.

Sendo assim, pode-se dizer que a cooperação influencia positivamente na percepção do relacionamento entre os colaboradores e empresa, ocasionando o crescimento e a qualificação nos produtos e/ou serviços oferecidos pela mesma e, consequentemente, possibilitando obter um melhor reconhecimento no mercado.

\section{Considerações finais}

Com o decorrer do processo de globalização da economia as Cooperativas acabam enfrentando certos riscos e precisam ser cada vez mais competitivas para poder sobreviver no mercado e cumprir suas metas. Dessa forma, o clima organizacional influencia na capacidade da empresa conseguir enfrentar os riscos do mercado globalizado e cumprir suas metas, pois o clima está vinculado com a motivação dos funcionários e com o trabalho em equipe.

Através da pesquisa realizada foi possível verificar que, por um lado a comunicação do chefe para com os funcionários está clara no sentido de passar as informações relativas ao trabalho. Entretanto, a opinião dos funcionários encontra-se dividida quanto à existência de problemas mais específicos de comunicação entre o chefe e os funcionários.

Por outro lado, constatou-se que não existem problemas de comunicação dos funcionários entre seus pares. Portanto, para solucionar os problemas ainda existentes, sugere-se que os mesmos sejam identificados e tratados pelo gerente em reuniões, pois uma boa comunicação influencia em melhores relacionamentos e desempenho das atividades.

Em relação ao trabalho em equipe, pode-se perceber a existência de um relacionamento de respeito e cooperação entre os colegas de trabalho e que os membros da equipe colaboram na realização das atividades, proporcionando um nível de satisfação elevado que reforça a boa comunicação. Embora exista um relacionamento de cooperação entre os colegas de trabalho acredita-se que esse relacionamento pode ser melhorado. Para isso, recomenda-se uma maior conscientização da importância do trabalho em equipe através de um treinamento efetivo com esse propósito.

Sobre a análise no que se refere à atuação do chefe, identificou-se que o mesmo possui a capacidade de influenciar e motivar a equipe de trabalho, pois os funcionários estão motivados e comprometidos com os objetivos e metas da Cooperativa e que os mesmos concordam que o seu trabalho é reconhecido e valorizado. Apesar dos resultados positivos, aconselha-se que a gerência procure buscar uma melhoria contínua através do diálogo com os seus funcionários.

Com relação ao salário proporcionado pela Cooperativa, observou-se que os funcionários acreditam que ele não corresponde ao mercado de trabalho e que não é justo de acordo com o desempenho de cada um na organização. Já com base nos benefícios proporcionados pela Cooperativa, os funcionários julgam que não atendem as necessidades pessoais e que a mesma não possui programas de incentivo para a evolução na carreira.

Portanto, considerando que a motivação faz com que os trabalhadores tenham vontade de exercer $o$ seu trabalho da melhor forma possível propõe-se que a Cooperativa disponibilize um plano de carreira para seus funcionários proporcionando um salário diferenciado de acordo com suas competências.

Dessa forma, os funcionários se sentirão mais motivados para produzir mais, o que por sua vez, proporcionará melhores resultados para a Cooperativa, onde por meio desse reconhecimento será possível também satisfazer as necessidades pessoais. Além disso, verificou-se que os funcionários concordam que os instrumentos e equipamentos são adequados para a execução do trabalho e que as condições físicas e de segurança estão boas.

Concluiu-se que, de modo geral, os funcionários estão satisfeitos com o clima organizacional pro- 
porcionado pela Cooperativa. Entretanto, conforme observado, ainda existem pontos que precisam ser melhorados. Por isso, se faz necessário sanar esses problemas identificados considerando a importância do clima organizacional para manter a motivação dos funcionários e não prejudicar o andamento das atividades, tampouco, com o convívio entre os membros da equipe.

Ao conquistar um clima organizacional positivo, isso permite melhores resultados e fortalece a Cooperativa para os desafios que o mercado oferece a todo o tipo de organização independentemente do porte ou ramo de atividade.

Sendo assim, ao findar esse trabalho, como sugestão de pesquisas futuras, sugere-se que esse estudo seja aplicado nos demais setores da Cooperativa para que a mesma tenha um melhor desempenho e que os gerentes continuem investindo no clima organizacional para que os funcionários se sintam mais satisfeitos e comprometidos com seu trabalho e com a organização no qual fazem parte.

Ainda, recomenda-se uma análise desse tipo em outras Cooperativas do Estado do Rio Grande do Sul considerando a importância do tema para o bom andamento das atividades entre os colaboradores e cooperados, bem como entre os gestores.

\section{Referências}

AZEVEDO, P. F. Comercialização de produtos agroindustriais. In: BATALHA, M. O. (Org.). Gestão agroindustrial. São Paulo: Atlas, 2010.

BAGGIO, L. R. A cooperação faz a força. Revista Fae Business, Blumenau, n. 12, p. 8-11, set. 2005.

BENSON, T. Building good management practices in Ethiopian agricultural cooperatives through regular financial audits. Journal of Co-operative Organization and Management, v. 2, n. 2, p. 7282, December 2014.

BISPO, C. A. F. Um novo modelo de pesquisa de clima organizacional. Revista Produção, v. 16, n. 2, p. 258-273, maio/ago. 2006.

DENISON, D. Cultura corporativa y productividad organizacional. Colombia: Legis, 1991.
DIAS, V.; STOCCO, J. A. P. Motivação no ambiente de trabalho: um estudo em uma instituição de ensino superior. Secretariado Executivo em Revist@, Passo Fundo, v. 2, p. 1-22, 2006.

DUBRIN, A. J. Princípios da administração. Rio de Janeiro: LTC, 1998.

GIL, A. C. Como elaborar projetos de pesquisa. 5. ed. São Paulo: Atlas, 2010.

GONSALVES, E. P. Conversas sobre iniciação à pesquisa científica. 4. ed. Campinas: Alínea, 2012 .

HASHIMOTO, M. Organizações intraempreendedoras: construindo a ponte entre clima interno e desempenho superior. 363 f. 2009. Tese (Doutorado em Administração de Empresas) Escola de Administração de Empresas de São Paulo - Fundação Getúlio Vargas, São Paulo, 2009.

JESUS, P.; TIRIBA, L. Cooperação. In: CATTANI, A. D. (Org.). A outra economia. Porto Alegre: Veraz Editores, 2003.

LUZ, R. S. Gestão do clima organizacional. 2. ed. Rio de Janeiro: Qualitymark, 2007.

MAIA, W. B. da; HARTMANN, T. C.; BUENO, B. A. F.; KAPP JUNIOR, C. Proposição de um plano de gerenciamento logístico em uma cooperativa agrícola paranaense. Revista de Gestão e Organizações Cooperativas, Santa Maria, v. 1, n. 2, 2014.

MAXIMIANO, A. C. A. Introdução à administração. 8. ed. São Paulo: Atlas, 2011.

MEGIDO, J. L. T.; XAVIER, C. Marketing e agribusiness. 3. ed. São Paulo: Atlas, 2003.

MICHEL, M. H. Metodologia e pesquisa científica em ciências sociais: um guia prático para acompanhamento da disciplina e elaboração de trabalhos monográficos. 2. ed. São Paulo: Atlas, 2009.

NANTES, J. F. D.; SCARPELLI, M. Elementos de gestão na produção rural. In: BATALHA, M. O. 
(Org.). Gestão agroindustrial. São Paulo: Atlas, 2010.

PINHO, D. B. Manual de cooperativismo: o pensamento cooperativo e o cooperativismo brasileiro. São Paulo: CNPq, 1982.

PINTO, Z. M. L. da S.; GOMES, C. F. S. O efeito da liderança na manutenção de servidores públicos de uma instituição federal de ensino. In: CONGRESSO NACIONAL DE EXCELÊNCIA EM GESTÃO, 10., 2014. Anais... Niterói: CNEG, 2014.

POLÔNIO, W. A. Manual das sociedades cooperativas. 4. ed. São Paulo: Atlas, 2004.

ROBBINS, S. P. Administração: mudanças e perspectivas. São Paulo: Saraiva, 2000.

RODRIGUES, R. O cooperativismo na globalização: gestão cooperativa. Belo Horizonte: OCEMG, 1997.

RÜDIGER, F. Introdução à teoria da comunicação: problemas correntes e autores. São Paulo: Edicon, 2003.

SCHMIDT, D.; VERGÍlLIO, P. Cooperativismocooperativa. In: CATTANI, A. D. (Org.). A outra economia. Porto Alegre: Veraz Editores, 2003.

SOARES NETO, B. Agronegócio cooperativo. In: BATALHA, Mário Otávio. (Org.). Gestão agroindustrial. São Paulo: Atlas, 2010.

STONER, J. A.; FREEMAN, E. R. Administração. Rio de Janeiro: Prentice Hall, 1995.

SULBARÁN, J. El rol de la gerencia en los procesos de cambio. Revista de Economía, n. 14, p. 193-206, 2002. 